\title{
Radiation dose escalation in stage III non-small-cell lung cancer
}

\author{
Breanne Terakedis ${ }^{1}$ and William Sause ${ }^{2}$ * \\ 1 Department of Radiation Oncology, Huntsman Cancer Hospital, Salt Lake City, UT, USA \\ ${ }^{2}$ Department of Radiation Oncology, Intermountain Medical Center, Salt Lake City, UT, USA
}

\author{
Edited by: \\ Martin J. Edelman, University of \\ Maryland Greenebaum Cancer \\ Center, USA \\ Reviewed by: \\ Daniel Gomez, MD Anderson Cancer \\ Center, USA \\ Joe Chang, MD Anderson Cancer \\ Center, USA \\ ${ }^{*}$ Correspondence: \\ William Sause, Department of \\ Radiation Oncology, Intermountain \\ Medical Center, 5131 South \\ Cottonwood Street, Murray, UT 84107, \\ USA. \\ e-mail:william.sause@imail.org
}

For patients with stage III non-small-cell lung cancer with unresectable or inoperable tumors, definitive chemoradiotherapy is often utilized. Historically, local control and overall survival rates have been poor. In an effort to improve local control, new chemotherapeutic agents in combination with higher doses of radiotherapy have been investigated. Early dose escalation trials date back to the 1980s, and the feasibility and efficacy of dose escalation for patients with inoperable stage III lung cancer continue to be topics of investigation. Herein, we review the evolution of chemotherapy as it relates to treatment of unresectable stage III lung cancer, and we outline the early and the more recent dose escalation studies. While dose escalation appears to provide a modest benefit in terms of preventing local failure and improving overall survival, advances in diagnostic imaging and radiotherapy treatment have possibly resulted in selection of a more favorable patient population. These variables make statements regarding the benefit of dose escalation challenging.

Keywords: radiotherapy, dose escalation, non-small-cell lung cancer, stage III

\section{INTRODUCTION}

Lung cancer is the most common type of cancer worldwide and is the leading cause of death due to cancer (American Cancer Society, 2007). An estimated 1.5 million new cases were expected in 2007 , and 975,000 men and 376,000 women were projected to die of their disease. The incidence of lung cancer is highest in North America, Eastern Europe, and China. Surgery, and more recently stereotactic body radiotherapy, is the standard of care for patients with non-small-cell lung cancer (NSCLC) operable AJCC stage I-III patients. Unfortunately, $30-40 \%$ of patients present with locally advanced stage III and IV disease, and overall survival rates for this cohort of patients ranges from 1 to 2 year. For patients with Stage III or IV NSCLC who have unresectable or inoperable tumors, definitive chemoradiotherapy is typically utilized. The timing of chemotherapy and radiotherapy (chemo-RT), and optimal chemotherapeutic agents and radiation dose have been the focus of numerous clinical trials. Historically, a minimum of $60 \mathrm{~Gy}$ has been considered standard for definitive treatment due to results from the landmark clinical trial, RTOG 73-01. In this study, 378 patients with inoperable or unresectable stage III NSCLC were randomized to receive a dose of $40 \mathrm{~Gy}$ split-course or radiotherapy to 40,50 , or $60-\mathrm{Gy}$ in a continuous course at $2 \mathrm{~Gy}$ per fraction. Rates of local failure correlated with radiation doses, with an improvement seen with dose escalation: $52 \%$ with $40 \mathrm{~Gy}, 41 \%$ with $50 \mathrm{~Gy}$, and $30 \%$ with $60 \mathrm{~Gy}$ (Perez et al., 1982). While $60 \mathrm{~Gy}$ proved to be more effective than $40 \mathrm{~Gy}$ in preventing a local failure, rates remained high. Le Chevalier et al. used chest $\mathrm{x}$-ray imaging as well as visual inspection and histologic examination using fiberoptic bronchoscopy to evaluate response to chemo-RT in patients with NSCLC. Local control rates were poor, in the range of $15-17 \%$ at 1 year (Le Chevalier et al., 1991). A metaanlysis by Auperin et al. (2010) reported an increase in OS in patients receiving concurrent
chemo-RT, and this was attributed to an increase in locoregional control. Local control in patients with lung cancer remains difficult to assess, and often the absence of disease progression is used to identify a successful treatment regimen.

For many decades, radiotherapy to 60 Gy was the standard of care. More recently, several studies have addressed the safety and efficacy of treating patients with NSCLC with higher doses of radiation therapy. Herein, we hope to summarize the early dose escalation studies for NSCLC and to describe the recent Phase I-III studies which have addressed this topic.

\section{CHEMOTHERAPY}

\section{INDUCTION CHEMOTHERAPY}

It is difficult to discuss radiotherapy for unresectable/inoperable Stage III lung cancer without describing the role of induction or concurrent chemotherapy. As previously mentioned, RTOG 7301 established radiotherapy as the standard of care for treatment of locally advanced NSCLC. Radiotherapy alone remained the standard of care until the CALGB published their results using induction chemotherapy (CALGB 84-33). This randomized trial was designed to evaluate the benefit of adding induction cisplatin $\left(100 \mathrm{mg} / \mathrm{m}^{2}\right.$ on days 1 and 29$)$ and vinblastine $\left(5 \mathrm{mg} / \mathrm{m}^{2}\right.$ on days 1 , $8,15,22$, and 29) chemotherapy to the standard radiotherapy regimen of $60 \mathrm{~Gy}$ in 30 fractions. A total of 78 patients were enrolled on the chemo-RT arm and 77 on the RT alone arm. After 7 years of follow-up, the median survival was greater in the chemo-RT group (13.7 months) than in the RT alone group (9.6 months; $p=0.012$ ). The 5 -year survival for these patients was 17 and $6 \%$ respectively (Dillman et al., 1996).

RTOG 88-08 was initiated to confirm the results of CALGB 84-33 and to test the efficacy of hyperfractionated radiotherapy. This was a three arm trial in which 462 patients were randomized 
to $2 \mathrm{months}$ of induction cisplatin $\left(100 \mathrm{mg} / \mathrm{m}^{2}\right)$ and vinblastine $\left(5 \mathrm{mg} / \mathrm{m}^{2}\right)$ followed by $60 \mathrm{~Gy}$ of radiation delivered at $2 \mathrm{~Gy}$ per fraction or to $60 \mathrm{~Gy}$ of radiotherapy alone delivered at $2 \mathrm{~Gy}$ per fraction or to $69.6 \mathrm{~Gy}$ of radiotherapy alone given at $1.2 \mathrm{~Gy}$ per fraction BID. Patients were enrolled between 1989 and 1992 and followed for 5 years. Patients who received induction chemotherapy had an improvement in 5-year overall survival compared to patients who received RT alone ( $8 \%$ for chemo-RT, $5 \%$ for standard RT, 6\% for hyperfractionated RT; Sause et al., 2000). LeChevalier et al. randomized 353 patients to induction chemotherapy including vindesine $\left(1.5 \mathrm{mg} / \mathrm{m}^{2}\right.$ on days 1 and 2$)$, cyclophosphamide $\left(200 \mathrm{mg} / \mathrm{m}^{2}\right.$ on days $\left.2-4\right)$, cisplatin $\left(100 \mathrm{mg} / \mathrm{m}^{2}\right.$ on day 2 ), and lomustine $\left(50 \mathrm{mg} / \mathrm{m}^{2}\right.$ on day 2 and $25 \mathrm{mg} / \mathrm{m}^{2}$ on day 3 ) followed by radiation to $65 \mathrm{~Gy}$ or to radiotherapy alone. The 3 year survival rates were $4 \%$ in the RT alone group and $12 \%$ in the chemo-RT arm $(p<0.02)$. As previously mentioned, 2 year rates of local control were 17 and 15\% respectively (Le Chevalier et al., 1991) (Table 1). A meta-analysis by Pritchard and Anthony (1996) found that the relative risk of death with the addition of sequential chemotherapy to radiotherapy was $0.86,0.85$, and 0.80 at 1,2 , and 3 years respectively. While these studies confirmed the benefit of adding induction chemotherapy to radiotherapy, local control, and overall survival rates remained poor.

\section{SEOUENTIAL VS. CONCURRENT CHEMOTHERAPY}

Three large phase III trials evaluated the efficacy of sequential vs. concurrent chemotherapy (Table 2). Furuse et al. randomized 320 patients to two cycles of mitomycin $\left(8 \mathrm{mg} / \mathrm{m}^{2}\right)$, vindesine $\left(3 \mathrm{mg} / \mathrm{m}^{2}\right)$, and cisplatin $\left(80 \mathrm{mg} / \mathrm{m}^{2} ; \mathrm{MVP}\right)$ chemotherapy given every 28 days with a concurrent split-course of RT to 56 Gy or to two cycles of MVP followed by a continuous course of RT to $56 \mathrm{~Gy}$. The median survival was 16.5 months for the concurrent arm and 13.3 months for the sequential chemo-RT arm $(p=0.04)$, and the 5 -year survival was 15.8 vs. $8.9 \%$ respectively $(p=0.0001)$. Local control rates were $50 \%$ on the concurrent arm and $35 \%$ on the sequential arm ( $p=0.07$; Furuse et al., 1999).

RTOG 9410 was a three arm randomized trial for patients with unresectable Stage II-III NSCLC. A total of 595 patients were randomized to sequential chemo-RT with cisplatin $\left(100 \mathrm{mg} / \mathrm{m}^{2}\right)$ and vinblastine $\left(5 \mathrm{mg} / \mathrm{m}^{2}\right)$ followed by RT to $60 \mathrm{~Gy}$ (similar to

Table 1 | Randomized phase III studies of induction chemotherapy for unresectable, locally advanced NSCLC.

\begin{tabular}{|c|c|c|c|c|c|}
\hline Reference & Trial & $\begin{array}{l}\text { Number of } \\
\text { patients }\end{array}$ & $\begin{array}{l}\text { Induction } \\
\text { chemotherapy }\end{array}$ & $\begin{array}{l}\text { Radiation dose } \\
\text { (Gy)/\# fractions }\end{array}$ & $\begin{array}{l}\text { Median survival } \\
\text { (months) }\end{array}$ \\
\hline Dillman et al. (1996) & CALGB 84-33 & 155 & C-vinblastine & $60 / 30$ & 13.7 \\
\hline \multirow[t]{3}{*}{ Sause et al. (2000) } & RTOG 88-08 & 462 & C-vinblastine & $60 / 30$ & 13.2 \\
\hline & & & - & $60 / 30$ & 11.4 \\
\hline & & & - & $69.6 / 58$ & 12 \\
\hline & & & - & $65 / 26$ & 10 \\
\hline
\end{tabular}

C-vinblastine, cisplatin and vinblastine; VCPC, vindesine, lomustine, cisplatin, and cyclophosphamide.

Table 2 | Select studies comparing induction, concurrent, and consolidation chemotherapy for unresectable, locally advanced III NSCLC.

\begin{tabular}{|c|c|c|c|c|c|c|c|}
\hline \multirow[t]{2}{*}{ Reference } & \multirow[t]{2}{*}{ Trial } & \multirow[t]{2}{*}{ Number of patients } & \multicolumn{3}{|c|}{ Chemotherapy } & \multirow{2}{*}{$\begin{array}{l}\text { Radiation dose } \\
\text { (Gy)/\# of fractions }\end{array}$} & \multirow{2}{*}{$\begin{array}{l}\text { Median survival } \\
\text { (months) }\end{array}$} \\
\hline & & & Induction & Concurrent & Consolidation & & \\
\hline \multirow[t]{2}{*}{ Furuse et al. (1999) } & - & 320 & CMV & - & - & $56 / 28$ & 13.3 \\
\hline & & & - & CMV & - & $56 / 28$ & 16.5 \\
\hline \multirow[t]{2}{*}{ Fournel et al. (2005) } & - & 205 & C-vinorelbine & - & - & 66 & 14.5 \\
\hline & & & - & $\mathrm{CE}$ & C-vinorelbine & 66 & 16.3 \\
\hline \multirow[t]{3}{*}{ Curran et al. (2003) } & RTOG 9410 & 595 & C-vinblastine & - & - & $60 / 30$ & 14.6 \\
\hline & & & - & C-vinblastine & - & $60 / 30$ & 17 \\
\hline & & & - & $\mathrm{CE}$ & - & $69.6 / 58$ & 15.2 \\
\hline \multirow[t]{2}{*}{ Vokes et al. (2007) } & CALGB 9431 & 366 & CaT & CaT & - & $66 / 33$ & 14 \\
\hline & & & & $\mathrm{CaT}$ & - & $66 / 33$ & 12 \\
\hline \multirow[t]{3}{*}{ Belani et al. (2005) } & LAMP & 257 & CaT & - & - & $63 / 34$ & 12 \\
\hline & & & CaT & CaT & - & $63 / 34$ & 12.8 \\
\hline & & & - & CaT & CaT & $63 / 34$ & 16.1 \\
\hline
\end{tabular}

CMV, cisplatin, mitomycin, and vindesine; C-Vinorelbine, cisplatin and vinorelbine; C-vinblastine, cisplatin and vinblastine; CE, cisplatin and etoposide; CaT, carboplatin and paclitaxel. 
the CALBG 8433 induction chemotherapy arm) or to concurrent chemo-RT utilizing the same chemo and RT dose or to concurrent chemo-RT with cisplatin $\left(50 \mathrm{mg} / \mathrm{m}^{2}\right)$ and etoposide (50 $\mathrm{mg}$ BID) with RT to $69.6 \mathrm{~Gy}$ in $1.2 \mathrm{~Gy}$ fractions given BID. The median survival rates were 14.6 months (sequential arm), 17.0 months (concurrent arm), and 15.2 months (concurrent BID arm). The concurrent chemo-RT arm had a better 4-year overall survival than the sequential arm ( 21 vs. $12 \%, p=0.046$ ). The locoregional failure rates were $50 \%$ (sequential arm), 43\% (concurrent QD arm), and 34\% (concurrent BID arm). The BID RT arm had a higher rate of acute toxicity, but there was no difference in late toxicity among the groups (Curran et al., 2003).

Fournel et al. published a third trial comparing sequential vs. concurrent chemoradiotherapy, and they also tested the utility of consolidation chemotherapy. Patients were randomized to receive either two cycles of induction cisplatin $\left(120 \mathrm{mg} / \mathrm{m}^{2}\right)$ and vinorelbine $\left(30 \mathrm{mg} / \mathrm{m}^{2}\right)$ followed by $66 \mathrm{~Gy}$ or to two cycles of concurrent cisplatin $\left(20 \mathrm{mg} / \mathrm{m}^{2}\right)$ and etoposide $\left(50 \mathrm{mg} / \mathrm{m}^{2}\right)$ with RT to $66 \mathrm{~Gy}$ followed by two cycles of consolidation cisplatin $\left(80 \mathrm{mg} / \mathrm{m}^{2}\right)$ and vinorelbine $\left(30 \mathrm{mg} / \mathrm{m}^{2}\right)$. Local control was higher in the concurrent arm (40 vs. $24 \%$ ). The 2 - and 4 -year overall survival rates trended toward improvement in the concurrent arm (were 26.5 and $14.2 \%$, respectively, in the sequential arm and 39.3 and $20.7 \%$, respectively) however were not statistically different. The median survival rates ( 14.5 months for the sequential arm, 16.3 months for the concurrent arm, $p=0.24$ ) were similar to those published by Furuse et al. (1999) and the overall survival rates were comparable to those from RTOG 94-10 (Fournel et al., 2005).

These three phase III clinical trials established concurrent chemo-RT as the standard of care for patients with unresectable/inoperable Stage III lung cancer. This is supported by work by Schaake-Koning et al. who compared radiotherapy with cisplatin given either daily $\left(6 \mathrm{mg} / \mathrm{m}^{2}\right)$ or weekly $\left(30 \mathrm{mg} / \mathrm{m}^{2}\right)$ to treatment with radiotherapy alone. Radiation was given in a splitcourse fashion to a total of $55 \mathrm{~Gy}$. There was an improvement in survival with daily cisplatin chemoradiotherapy compared to radiotherapy alone $(p=0.009)$. There was no significant difference in survival when the weekly cisplatin group was compared with the radiotherapy alone group. There was an improvement in progression free survival in those treated with cisplatin yet no difference in distant metastases suggesting that obtainment of local control can lead to higher rates of overall survival (Schaake-Koning et al., 1992).

A metaanlysis by Auperin et al. compiled data from six trials (CALGB 8831, WJLCG, RTOG 9410, GMMA Ankara, GLOT_GFPC NPC 95-01, EORTC 08972) including 1205 patients to evaluate the benefit of concomitant vs. sequential chemoradiotherapy. Concomitant chemo-RT was associated with a $4.5 \%$ absolute survival benefit at 5 years. There was an improvement in locoregional progression free survival ( $6 \%$ at 5 years, HR 0.777 ) but no difference in the rate of distant metastases (40\%, HR 1.04), thereby highlighting the importance of local control in promoting survival (Auperin et al., 2010).

More recently, cisplatin chemotherapy has been replaced by regimens which are believed to more effective and less toxic based on Phase II studies. CALGB 39801, a phase III study, randomized 366 patients to two cycles of induction chemotherapy with paclitaxel $\left(200 \mathrm{mg} / \mathrm{m}^{2}\right)$ and carboplatin $(\mathrm{AUC}=6)$ every 3 weeks followed by paclitaxel $\left(50 \mathrm{mg} / \mathrm{m}^{2}\right)$ and carboplatin $(\mathrm{AUC}=2)$ with RT to $66 \mathrm{~Gy}$ or to the same treatment without induction chemotherapy. Unfortunately, the median survival was only 12 months without induction chemotherapy and 14 months with induction chemotherapy ( $p=0.3$; Vokes et al., 2007). Regardless, many of the more recent studies including RTOG 0117 and CALGB 30105 have utilized carboplatin and paclitaxel based regimens and have shown promising results.

\section{CONSOLIDATION CHEMOTHERAPY}

Use of consolidation chemotherapy has been studied in several randomized phase III trial including the trial by Fournel et al. (2005) as mentioned above. The locally advanced multimodality protocol (LAMP) trial was a phase II, three arm study evaluating treatment with two cycles of induction carboplatin (AUC 6) and paclitaxel $\left(200 \mathrm{mg} / \mathrm{m}^{2}\right)$ followed by $63 \mathrm{~Gy}$ RT or to two cycles of the same chemotherapy followed by concurrent weekly carboplatin (AUC 2) and paclitaxel $\left(45 \mathrm{mg} / \mathrm{m}^{2}\right)$ with RT to $63 \mathrm{~Gy}$ or to the same concurrent chemo-RT followed by consolidation carboplatin (AUC 6) and paclitaxel $\left(200 \mathrm{mg} / \mathrm{m}^{2}\right)$. The median survival times for the three arms were $13,12.8$, and 16.1 months respectively (Belani et al., 2005). SWOG conducted a trial (9019) using concurrent cisplatin $\left(50 \mathrm{mg} / \mathrm{m}^{2}\right)$, etoposide $\left(50 \mathrm{mg} / \mathrm{m}^{2}\right)$, and radiation therapy ( $45 \mathrm{~Gy}$ ). In the absence of metastatic disease, patients received additional cisplatin and etoposide, and radiation therapy was delivered to a total of $61 \mathrm{~Gy}$. This regimen resulted in a median survival of 15 months (Albain et al., 2002). They conducted a similar trial, SWOG 9504, using docetaxel for consolidation, and the median survival was 26 months (Gandara et al., 2003). A phase III study by the Hoosier Oncology Group (HOG) evaluated the effects of consolidation with docetaxel and found no survival benefit and increased complication rates with docetaxel (Hanna et al., 2008).

\section{DOSE ESCALATION IN THE THREE-DIMENSIONAL CONFORMAL RADIOTHERAPY ERA}

Despite the benefit obtained by adding concurrent and consolidation chemotherapy to radiotherapy regimens, local control, and overall survival rates remain poor. Escalation of radiotherapy doses has been employed to improve overall survival by both preventing local progression of disease and eliminating a source for distant metastases. Dose escalation is possible due to improvements in diagnostic imaging and radiotherapy techniques over the past 40 years. In early RT studies such as RTOG 73-01, CALGB 8433, RTOG 88-08, and RTOG 9410, RT treatment plans were based on plain film imaging. Treatment fields were designed to encompass gross tumor as well as elective nodes. Currently, radiation oncologists may use PET-CT imaging to precisely define tumor and involved nodal volumes and three dimensional conformal radiotherapy (3D-CRT) and Intensity-modulated radiation therapy (IMRT) to deliver radiotherapy.

\section{POSITRON EMISSION TOMOGRAPHY}

PET-CT imaging should be used whenever available for patients who will undergo definitive RT for stage III NSCLC. It can be used to identify patients with distant metastases (up to $20 \%$ of clinical Stage III patients) and patients who have locally advanced disease not amenable to surgery (MacManus et al., 2001). PET-CT 
imaging can guide radiotherapy planning and allow for treatment of only the primary and involved nodes. Using mediastinoscopy or thoracotomy to confirm nodal involvement, Darling et al. (2011) report that the sensitivity of PET imaging is $70 \%$ and the specificity is $94 \%$. In a meta-analysis by Toloza et al. (2003), the sensitivity and specificity of mediastinal staging was 84 and $89 \%$, respectively, for PET imaging compared to 57 and 84\%, respectively, for CT imaging.

Bradley et al. (2005) evaluated radiotherapy treatment volumes as contoured on CT imaging vs. volumes contoured PET-CT imaging. Twenty-six patients with Stage I-III NSCLC underwent sequential CT and FDG-PET simulation. PET imaging altered treatment volumes in 14 (58\%) patients; it was useful in distinguishing tumor from atelectasis in three cases leading to a decrease in treatment volume, and 10 patients were found to have nodal disease undetected on CT imaging alone, leading to an increase in treatment volume. At the University of Michigan, 14 patients with locally advanced NSCLC underwent PET-CT imaging midway through a course of definitive radiotherapy. The mean decrease in tumor volume as seen on mid-treatment PET-CT was 44\%, and this information was used to escalate the RT dose and to reduce dose to normal tissue (Feng et al., 2009). The RTOG is planning a phase II trial (RTOG 1106) of adaptive radiation using duringtreatment FDG-PET/CT to direct dose escalation for NSCLC. While PET-CT imaging has allowed for more accurate staging of patients with NSCLC, increased exclusion of high risk patients with disease outside the thorax poses a challenge when attempting to compare modern day randomized clinical trials to historical trials of the past.

\section{ELECTIVE LYMPH NODE IRRADIATION}

Traditionally, before the widespread use of CT imaging, radiotherapy treatment fields were designed to encompass bilateral hilar and mediastinal lymph nodes, regardless of their involvement. With CT and PET-CT imaging, better assessment of the locoregional nodal burden is feasible. In addition, several studies have shown that omitting elective nodal irradiation (ENI) does not compromise local control or overall survival. ENI irradiation makes dose escalation difficult due to the radiosensitivity of normal lung tissue. In an effort to determine the necessity of ENI, Yuan et al. randomized 200 patients to cisplatin-based chemoradiotherapy with treatment of either elective nodes (RT 60-64 Gy) or involved node irradiation (68-74 Gy). Patients in the involved field arm had a better overall response rate ( 90 vs. $79 \%, p=0.032$ ) and improved 6 -year local control rate ( 51 vs. $36 \%, p=0.032$ ). There was a significant overall survival benefit for elective node irradiation at 2 years $(39.4$ vs. $25.6 \%, p=0.048)$ but not at 1 or 5 years. The rate of radiation pneumonitis was lower in patients who received involved field radiation ( 17 vs. $29 \%, p=0.044$; Yuan et al., 2007). Elective nodal failure occurred in $4 \%$ of patients in the ENI group and $7 \%$ of the patients in the INI group $(p=0.352)$. The elective nodal failure rate in patients treated without ENI ranges from 4 to 7\% (Rosenzweig et al., 2001; Sulman et al., 2009).

\section{THREE DIMENSIONAL CONFORMAL}

\section{RADIOTHERAPY/INTENSITY-MODULATED RADIOTHERAPY}

Radiotherapy techniques have drastically changed over the past several decades. Many of the trials evaluating chemo-RT for Stage
III lung cancer were performed in the era of two dimensional radiotherapy. The advent of CT based planning in conjunction with increasing sophistication of linear accelerators have allowed for improvement in precision of 3D-CRT plans. 3D-CRT has allowed for quantification of dose to normal structures thereby leading to standardization of dose constraint limits. This has allowed for more ubiquitous treatment amongst radiation oncology facilities. Intensity-modulated radiation therapy (IMRT) has been studied as a potential mechanism for allowing dose escalation. Lievens et al. (2011) performed a dose escalation planning study in which 3D and IMRT plans were created for 35 patients with NSCLC treated to 66 Gy. IMRT resulted in significant decreases in mean lung and maximal spinal cord doses, however esophageal doses were increased. Four-dimensional imaging with motion tracking and control, daily on-board imaging, and adaptive radiotherapy are all areas of intense interest and research. While these are enormous topics in and of themselves, suffice it to say that these technologies have, and will continue to allow us to create more conformal radiotherapy plans while minimizing dose to critical structures. As this is accomplished, dose escalation will ideally lead to more effective treatment without excessive toxicity.

\section{EARLY TRIALS OF DOSE ESCALATION}

One of the earliest dose escalation trials for inoperable/unresectable Stage III NSCLC was RTOG 8311, a phase I/II trial of hyperfractionated RT. Patients were randomized to receive $60,64.8$, or 69.6 Gy at 1.2 Gy per fraction. After an initial toxicity analysis revealed acceptable risks, patients were randomized to 74.4 or $79.2 \mathrm{~Gy}$. In total, 848 patients were randomized, and there was no significant difference in acute or late toxicity, including the risk of radiation pneumonitis. Patients who were treated to at least $69.6 \mathrm{~Gy}$ had a better median survival (13 months) than those treated to lower doses (Cox et al., 1990). There was no difference in survival amongst the five arms, however when the authors included 350 patients from CALGB 84-33 who met the same eligibility criteria, they found that treatment to $69.6 \mathrm{~Gy}$ resulted in a better median survival than those treated to with RT alone to a lower total dose. From 1983 to 1989, Arriagada et al. randomized 353 patients to RT alone to 65 Gy or to RT to 65 Gy with neoadjuvant and adjuvant VCPC (vindesine, cyclophosphamide, cisplatin, lomustine) chemotherapy. The 2-year survival rate was $14 \%$ in the $\mathrm{RT}$ alone group and $21 \%$ in the chemo-RT group $(p=0.08)$. The local control rate at 1 year was 17 and $15 \%$. While local control and survival remained poor, these studies demonstrated that treatment to 65 Gy was feasible (Arriagada et al., 1991).

Based on the dose escalation trials of the 1970s and 1980s including RTOG 73-01, RTOG 83-11, and the work by Arriagada et al. (1991) the RTOG opened a radiation only, dose escalation study, RTOG 93-11. Patients were randomized to one of four radiotherapy doses $(70.9,77.4,83.8,90.3 \mathrm{~Gy}, 2.1 \mathrm{~Gy}$ per fraction) based on the lung V20 (volume of the lung that receives $20 \mathrm{~Gy}$ ). There were two treatment related deaths in the $90.3 \mathrm{~Gy}$ arm, and therefore this was deemed too toxic. Radiation dose was safely escalated to $83.8 \mathrm{~Gy}$ for patients with a V20 $<25 \%$ and to $77.4 \mathrm{~Gy}$ for patients with a V20 between 25 and 36\% (Bradley et al., 2005). The University of Michigan performed a dose escalation trial in which they randomized 106 patients with NSCLC Stage I-III to 
63-103 Gy in 2.1 Gy per fraction. ENI was not performed and 3DCRT was used for treatment delivery. The majority of the patients did not receive chemotherapy. Median survival was 19 months, and multivariate analysis revealed that radiation dose was a predictor of OS $(p=0.0006)$. The 5 -year OS rate was 4,22 , and $28 \%$ for patients receiving 63-69, 74-84, and 92-103 Gy, respectively (Kong et al., 2005).

\section{RATIONALE FOR DOSE ESCALATION TO 74 Gy}

The University of North Carolina has undertaken several studies to evaluate dose escalation and the role of chemotherapy. A Phase I/II trial reported by Rosenman et al., 2002) reported on 62 patients with Stage III NSCLC treated with two cycles of induction carboplatin (AUC 6) and paclitaxel $(225 \mathrm{mg} / \mathrm{m} 2)$ followed by concurrent weekly carboplatin (AUC 2) paclitaxel $\left(45 \mathrm{mg} / \mathrm{m}^{2}\right.$ ) with radiation doses escalated from 60 to $74 \mathrm{~Gy}$. The median survival was 24 months, and $38 \%$ of patients were alive at 3 years. While there was not an association between dose and overall survival, the authors concluded that RT to 74 Gy was safe and could possibly contribute to lengthening survival (Rosenman et al., 2002). The University of North Carolina continued their dose escalation work, and in 2004 Socinksi et al. reported on a phase I dose escalation study to doses of 78, 82, 86, and 90 Gy. Patients received induction chemotherapy with carboplatin $(\mathrm{AUC}=5)$, irinotecan $\left(100 \mathrm{mg} / \mathrm{m}^{2}\right)$, and paclitaxel $\left(175 \mathrm{mg} / \mathrm{m}^{2}\right)$ followed by weekly carboplatin $(\mathrm{AUC}=2)$ and paclitaxel $\left(45 \mathrm{mg} / \mathrm{m}^{2}\right)$ with radiotherapy. RT dose was escalated without dose limiting toxicity, and the median survival was 24 months (Socinski et al., 2004). The NCCTG performed a dose escalation study in which 15 patients were treated with weekly carboplatin $(\mathrm{AUC}=2)$ and paclitaxel $\left(50 \mathrm{mg} / \mathrm{m}^{2}\right)$ and dose escalated radiotherapy from 70 to $78 \mathrm{~Gy}$. Two dose limiting toxicities occurred in the four patients treated to $78 \mathrm{~Gy}$, and therefore the maximum tolerated dose, as reported by Rosenman et al. was determined to be $74 \mathrm{~Gy}$. The median survival was 37 months (Schild et al., 2006).

As previously mentioned, it was established that concurrent chemoradiotherapy was preferable to sequential chemotherapy followed by radiotherapy or to radiotherapy alone, and therefore the RTOG initiated a phase I dose escalation study, RTOG 0117 , to evaluate maximum tolerated radiation doses in the setting of chemotherapy. A phase II component of this study was designed to determine survivorship at 12 months. The phase I trial was designed to dose escalate with increasing dose per fraction, beginning at 75.25 Gy in 2.15 Gy per fraction with concurrent weekly carboplatin (AUC $2 \mathrm{mg} / \mathrm{m}^{2}$ ) and paclitaxel $\left(50 \mathrm{mg} / \mathrm{m}^{2}\right.$ ). Eight patients were treated to $75.25 \mathrm{~Gy}$, and $75 \%$ developed grade $\geq 3$ toxicities. Due to these treatment related complications, the dose was de-escalated, and the maximum tolerated dose was determined to be 74 Gy (Bradley et al., 2010a). In the phase II portion of the study, 55 patients received $74 \mathrm{~Gy}$, and the median followup was 19.3 months. The median survival was 25.9 months, and $72.7 \%$ of patients were alive at 1 year. Twelve patients experienced grade $\geq 3$ lung toxicity (Bradley et al., 2010b).

The CALGB conducted a randomized phase II trail, CALGB 30105, to evaluate survival in patients with locoregionally advanced NSCLC cancer treated with 74 Gy of RT with induction and concurrent chemotherapy. Forty-three patients were treated with induction carboplatin $(\mathrm{AUC}=6)$ and paclitaxel $\left(225 \mathrm{mg} / \mathrm{m}^{2}\right)$ on days 1 and 22 followed by weekly carboplatin $(\mathrm{AUC}=2)$ and paclitaxel $\left(45 \mathrm{mg} / \mathrm{m}^{2}\right)$ with concurrent RT to $74 \mathrm{~Gy}$. Twenty-six patients were treated with induction carboplatin (AUC 5, days 1 and 22 ) and gemcitabine $\left(1000 \mathrm{mg} / \mathrm{m}^{2}\right.$, days $\left.1,8,22,29\right)$ followed by concurrent weekly gemcitabine $\left(35 \mathrm{mg} / \mathrm{m}^{2}\right)$ and radiotherapy to $74 \mathrm{~Gy}$. The primary end point was survival at 18 months. The gemcitabine arm was closed early due to a higher than expected rate of pulmonary toxicity. The median survival was 24.3 months for the carboplatin/paclitaxel arm, which was longer than expected, and 12.5 months for the gemcitabine arm (Socinski et al., 2008) (Table 3).

In addition to these prospective trials, retrospective studies have supported the use of higher doses of radiation in definitive treatment of locally advanced NSCLC. Wang et al. reported on 237 consecutive Stage III patients who were treated with RT alone $(n=106)$, sequential chemotherapy followed by RT $(n=69)$, or to concurrent chemotherapy and RT $(n=62)$. Median survival was $7.4,14.9$, and 15.8 months respectively. Both radiation dose and use of chemotherapy were predictors of overall survival (Wang et al., 2008). Machtay et al. analyzed the biologically effective dose of the radiotherapy treatment for 1356 patients treated on seven RTOG trials (RTOG 88-08, 90-15, 91-06, 92-04, 93-09, 94-10, and 98-010). There was a correlation between BED and both overall survival and local control. A 1-Gy BED increase was associated with a $4 \%$ improvement in survival, and a $1-G y$ tBED resulted in a 3\% improvement in locoregional control (Machtay et al., 2010).

These phase I/II trials and retrospective data have demonstrated a small, but important, improvement in overall survival for patients treated with concurrent chemotherapy and dose escalated radiotherapy. RTOG 0617 is a randomized, phase III, prospective clinical trial which was designed to confirm or refute the benefit of dose escalated RT. This started as a two arm trial with randomization to either concurrent weekly paclitaxel $\left(45 \mathrm{mg} / \mathrm{m}^{2}\right)$ and cisplatin $(\mathrm{AUC}=2)$ with either 60 or $74 \mathrm{~Gy}$ of radiation therapy at 2 Gy per fraction followed by two cycles of consolidation paclitaxel $\left(200 \mathrm{mg} / \mathrm{m}^{2}\right)$ and cisplatin $(\mathrm{AUC}=6)$. In 2008, the protocol was modified, and cetuximab was added to the randomization, thereby making RTOG 0617 a four arm randomized trial. In June of 2011, the high dose radiation arms ( $74 \mathrm{~Gy}$ ) were closed as an interim analysis revealed that the high dose radiotherapy arm could no longer show a survival benefit even with further accrual. This analysis did not identify particular safety concerns. The remaining two arms of the study which randomize patients to cisplatin, paclitaxel, and RT to $60 \mathrm{~Gy}$ with or without cetuximab are still open to accrual.

Evaluating the local control and overall survival benefit of dose escalation for patients with Stage III NSCLC can be quite challenging. Over the past several decades, the use of chemotherapy has increased, and resultantly patients who are unable to tolerate aggressive chemotherapeutic regimens have not been eligible for many of the recent Phase II and Phase III clinical trials. In addition, dose escalation is only made possible by the use of smaller field sizes and increased conformality of radiation therapy plans. Strict dose constraints guide daily practice, and therefore patients with large tumors are often excluded from trials because these patients cannot be treated without exceeding radiotherapy dose constraints. These factors lead to selection of patients with better performance status, fewer medical comorbidities, and smaller 
Table 3 | Select trials of dose escalation for Stage III inoperable non-small-cell lung cancer.

\begin{tabular}{|c|c|c|c|c|c|}
\hline Reference & Trial & $\begin{array}{l}\text { Number of } \\
\text { Patients }\end{array}$ & Chemotherapy & Radiation dose & Outcomes \\
\hline Perez et al. (1982) & RTOG 73-01 & 378 & - & $40,50,60 \mathrm{~Gy}$ & $\begin{array}{l}\text { Improvement in local control with } \\
\text { higher dose. }\end{array}$ \\
\hline Cox et al. (1990) & RTOG 8311 & 848 & - & $\begin{array}{l}<69.6 \mathrm{~Gy},>69.6 \mathrm{~Gy} \text {, } \\
\text { up to } 79.2 \mathrm{~Gy}\end{array}$ & $\begin{array}{l}\text { Improvement in median survival } \\
\text { (13 months) for > } 69.6 \mathrm{~Gy} \text {. }\end{array}$ \\
\hline Bradley et al. (2005) & RTOG 93-11 & 176 & - & 70.9-90.3 Gy & $\begin{array}{l}\text { 90.3 Gy maximum tolerated dose. } \\
\text { Established safety of dose escala- } \\
\text { tion based on lung } \vee 20 \text {. }\end{array}$ \\
\hline Kong et al. (2005) & - & 106 & - & 63-103 Gy & $\begin{array}{l}\text { OS improved with increasing dose. } \\
\text { MTD not reached. }\end{array}$ \\
\hline Rosenman et al. (2002) & - & 62 & $\begin{array}{l}\text { Induction and concurrent } \\
\mathrm{CaT}\end{array}$ & 60-74 Gy & $\begin{array}{l}74 \text { Gy was safe in setting of concur- } \\
\text { rent chemotherapy. }\end{array}$ \\
\hline Socinski et al. (2004) & - & 29 & $\begin{array}{l}\text { Induction CalT. Concur- } \\
\text { rent } \mathrm{CaT}\end{array}$ & 78-90 Gy & MTD not reached. \\
\hline Schild et al. (2006) & - & 15 & Concurrent $\mathrm{CaT}$ & 70-78 Gy & MTD 74 Gy. \\
\hline Bradley et al. (2010a) & $\begin{array}{l}\text { RTOG 0117, } \\
\text { Phase I }\end{array}$ & 17 & Concurrent $\mathrm{CaT}$ & Started at $75.25 \mathrm{~Gy}$ & $\begin{array}{l}\text { Significant grade } 3 \text { toxicity at } \\
75.25 \text { Gy. MTD determined to be } \\
74 \text { Gy. }\end{array}$ \\
\hline Socinski et al. (2008) & $\begin{array}{l}\text { CALGB } \\
30105\end{array}$ & 69 & $\begin{array}{l}\text { Induction and concurrent } \\
\mathrm{CaT} \text { v. induction CaGem } \\
\text { with concurrent Gem. }\end{array}$ & $74 \mathrm{~Gy}$ & $\begin{array}{l}\text { Closed early due to high toxi- } \\
\text { city with Gem. Median survival } \\
24.3 \text { months (CaT) vs. } 12.5 \text { months } \\
\text { (CaGem). }\end{array}$ \\
\hline
\end{tabular}

CaT, carboplatin and paclitaxel; CalT, carboplatin, irinotecan, and paclitaxel; Gem, gemcitabine; CaGem, carboplatin and gemcitabine.

tumors for enrollment on our clinical trials. Ultimately this will result in better outcomes than historical standards, however the comparative groups are not necessarily equivalent.

\section{TOXICITY ASSOCIATED WITH DOSE ESCALATION}

Dose escalation for lung cancer does not come without costs in terms of radiation induced damage to normal tissues. Lung and esophageal toxicity can be morbid and lead to death. Lee et al. published late toxicity data from the phase I/II dose escalation trials completed at the University of North Carolina. Eighty-eight patients who received $\geq 66$ Gy were included in the analysis. A total of 28 late complications were identified in 21 patients. The late complications were pulmonary $(n=8)$, esophageal $(n=6)$, cardiac $(n=9)$, osseous $(n=6)$, and a second primary $(n=2$; Lee et al., 2009). A secondary analysis of the CALGB 30105 trial (induction and concurrent chemotherapy with 74 Gy RT) found that, of the cases of RTOG grade 3-5 toxicity, $80 \%$ of patients had N3 disease or a V20 >38 (Salama et al., 2011). Graham et al. report that the grade $2+$ pneumonitis risk is $0 \%$ when the V20 is $<22$, $7 \%$ if the V20 is $22-31,13 \%$ if the V20 is $32-40$ and $36 \%$ if the $\mathrm{V} 20$ is $>40 \%$. It is recommended that the V20 should be $\leq 37 \%$ and the MLD $\leq 20$ Gy to reduce the risk of radiation pneumonitis (Graham et al., 1999).

\section{FUTURE DIRECTIONS PROTON THERAPY}

While most radiotherapy patients are treated with photon-based 3D-CRT or intensity-modulated radiotherapy, there has been an increase in the number of and the access to proton treatment facilities in the past decade. When treating any body site, dose to critical structures can be minimized by capitalizing on the Bragg Peak effect of proton beam therapy. This becomes especially important when tumor volumes are located in close proximity to radiosensitive structures such as normal lung, esophagus, and spinal cord. Several single institution studies have evaluated dosevolume histograms for treatment of NSCLC with either photon or proton therapy. Chang et al. compared proton to photon treatment plans for patients with stages I and III NSCLC. For 10 patients with stage I NSCLC, the mean lung dose, V5, V10, and V20 were 9.7 Gy, 31.8, 24.6, and 15.8\%, respectively, for 3D-CRT photon therapy with prescribed dose of $66,5.4 \mathrm{~Gy}, 13,11.7$, and $9.8 \%$, respectively, for photon therapy with a prescribed dose of 66 CGE $(p=0.002)$, and $7.3 \mathrm{~Gy}, 13.4,12.3$, and $10.9 \%$ for photon therapy with a prescribed dose of 87.5 CGE $(p=0.002)$. Similar patterns were seen for stage III patients treated with photon therapy to $63 \mathrm{~Gy}$ when compared to proton therapy prescribed to $63 \mathrm{CGE}$ and 74 CGE (Chang et al., 2006). IMRT planning was used in select cases, and the dose to critical structures in the photon IMRT plan still exceeded that of the proton treatment plans. Zhang et al. expanded on the utility of IMRT by comparing dose-volume histograms for IMRT to intensity-modulated proton therapy (IMPT) treatment plans for patients with stage IIIB NSCLC. IMPT planning allowed for increased sparing of the lung, heart, esophagus, and spinal cord (Zhang et al., 2010). While proton therapy appears superior in these dosimetric comparisons, the clinical value of proton treatment is still unknown. 
Widesott et al. (2008) reviewed the published literature on proton therapy for NSCLC and concluded that, because of the small number of institutions and studies addressing proton therapy for NSCLC, there is currently insufficient evidence to support the routine use of proton therapy over photon therapy.

\section{FUNCTIONAL IMAGE AND BIOMARKER-GUIDED TREATMENT}

While it is outside of the scope of this review to discuss, in detail, the emerging technologies and drug development research which are influencing treatment of unresectable NSCLC, it is important to mention these important advances. As previously discussed, use of FDG-PET CT imaging has allowed for improved diagnostic accuracy and treatment planning for NSCLC. In addition, nuclear medicine studies such as FDG-PET and functional magnetic resonance imaging and spectroscopy have been utilized to obtain biologic, functional, and metabolic characteristics of tumors. Ling et al. have proposed the idea of creating a "biological target volume" (BTV) in addition to the normal radiotherapy treatment planning structures. The BTV would encompass information from these functional studies and allow for targeting of dose escalated treatment toward regions of highly active tumor (Ling et al., 2000).

In addition to functional targeting, vast amounts of effort are being directed at identifying molecular targets and creating molecular therapies for cancer treatment. ERCC1 expression, mutation of the tyrosine kinase domain of the epidermal growth

\section{REFERENCES}

Albain, K. S., Crowley, J. J., Turrisi, A. T., Gandara, D. R., Farrar, W. B., Clark, J. I., Beasley, K. R., and Livingston, R. B. (2002). Concurrent cisplatin, etoposide, and chest radiotherapy in pathologic stage IIIB non-small-cell lung cancer: a Southwest Oncology Group phase II study, SWOG 9019. J. Clin. Oncol. 20, 3454-3460.

American Cancer Society. (2007). Global Cancer Facts and Figures 2007. Atlanta, GA: American Cancer Society, Inc.

Amundson, S. A., Do, K. T., Vinikoor, L. C., Lee, R. A., Koch-Paiz, C. A., Ahn, J., Reimers, M., Chen, Y., Scudiero, D. A., Weinstein, J. N., Trent, J. M., Bittner, M. L., Meltzer, P. S., and Fornace, A. J. Jr. (2008). Integrating global gene expression and radiation survival parameters across the 60 cell lines of the National Cancer Institute Anticancer Drug Screen. Cancer Res. 68, 415-424.

Arriagada, R., Le Chevalier, T., Quoix, E., Ruffie, P., de Cremoux, H., Douillard, J. Y., Tarayre, M., Pignon, J. P., and Laplanche, A. (1991). Effect of chemotherapy on locally advanced non-small cell lung carcinoma: a randomized study of 353 patients. Int. J. Radiat. Oncol. Biol. Phys. 20, 1183-1190.

Auperin, A., Le Pechoux, C., Rolland, E., Curran, W. J., Furuse, K., Fournel, P., Belderbos, J., Clamon, G., Ulutin, H.

factor receptor, and inhibition of the PI3K pathway have lead to increased radiosensitivity in cell lines (Das et al., 2010). Several investigators have attempted create predictive models of radiation sensitivity by identifying a set of genes involved in radiation response (Torres-Roca et al., 2005; Amundson et al., 2008; Eschrich et al., 2009). In the future, it is possible that these predictors of radiosensitivity will allow for tailoring of radiation treatment dose to individual patients.

\section{CONCLUSION}

Dose escalation in NSCLC remains a viable avenue of investigation. The contribution of systemic agents, radiotherapy dose, and patient selection make statements regarding the benefit of dose escalation challenging. As the aggressiveness of chemo-RT increase, toxicity increases, and patient selection undoubtedly leads to the improvements reported in Phase II clinical trials. While the interim analysis of RTOG 0617 appears to show no survival benefit to dose escalated RT to $74 \mathrm{~Gy}$, investigators continue to try to improve on the low survival rates of patients with Stage III NSCLC. Unresectable and inoperable Stage III NSCLC continues to provide a challenge for radiation oncologists and medical oncologists worldwide. Dose escalation, in some settings has proven to be associated with an overall survival benefit, while in other trials, there has been no benefit to dose escalation. This review was aimed at summarizing the chemo-RT data which guide current practice.

to III non-small-cell lung cancer: phase I results of RTOG 0117. Int. J. Radiat. Oncol. Biol. Phys. 77, 376-372.

Bradley, J. D., Bae, K., Graham, M. V., Byhardt, R., Govindan, R., Fowler, J., Purdy, J. A., Michalski, J. M., Gore, E., and Choy, H. (2010b). Primary analysis of the phase II component of a phase I/II dose intensification study using three-dimensional conformal radiation therapy and concurrent chemotherapy for patients with inoperable non-small-cell lung cancer: RTOG 0117. J. Clin. Oncol. 28, 2475-2480.

Chang, J. Y., Zhang, X., Wang, X., Kang, Y., Riley, B., Bilton, S., Mohan, R., Komaki, R., and Cox, J. D. (2006). Significant reduction of normal tissue dose by proton radiotherapy compared with three-dimensional conformal or intensity-modulated radiation therapy in stage $\mathrm{I}$ or III non-small-cell lung cancer. Int. J. Radiat. Oncol. Biol. Phys. 65, 1087-1096.

Cox, J., Azarnia, N., Byhardt, R. W. Shin, K. H., Emami, B., and Pajak, T. F. (1990). A randomized phase I/II trial of hyperfractionated radiation therapy with total doses of 60.0 Gy to 79.2 Gy: possible survival benefit with $\geq 69.6$ Gy in favorable patients with Radiation Therapy Oncology Group stage III nonsmall-cell lung carcinoma: report of Radiation Therapy Oncology Group 83-11. J. Clin. Oncol. 8, 1543-1555.

Curran, W., Scott, C., Langer, C., et al. (2003). Long-term benefit is observed in a phase III comparison of sequential v. concurrent chemoradiation for patients with unresectable NSCLC: RTOG 9410. Am Soc. Clin. Oncol. 22, 621a.

Darling, G. E., Maziak, D. E., Inculet, R. I., Gulenchyn, K. Y., Driedger, A. A., Ung, Y. C., Gu, C. S., Kuruvilla, M. S., Cline, K. J., Julian, J. A., Evans, W. K., and Levine M. N. (2011). Positron emission tomography-computed tomography compared with invasive mediastinal staging in non-small cell lung cancer: results of mediastinal staging in the early lung positron emission tomography trial. J. Thorac. Oncol. 6, 1367-1372.

Das, A. K., Bell, M. H., Nirodi, C. S., Story, M. D., and Minna, J. D. (2010). Radiogenomics-predicting tumor responses to radiotherapy in lung cancer. Semin. Radiat. Oncol. 20, 149-155.

Dillman, R. O., Herndon, J., Seagren, S. L., Eaton, W. L. Jr., and Green M. R. (1996). Improved survival in stage III non-small-cell lung cancer: seven-year follow-up of Cancer and Leukemia Group B (CALGB) 8433 Trial. J. Natl. Cancer Inst. 88, 1210-1215. 
Eschrich, S., Zhang, H., Zhao, H., Boulware, D., Lee, J. H., Bloom, G., and Torres-Roca, J. F. (2009). Systems biology modeling of the radiation sensitivity network: a biomarker discovery platform. Int. J. Radiat. Oncol. Biol. Phys. 75, 497-505.

Feng, M., Kong, F. M., Gross, M., Fernando, S., Hayman, J. A., and Ten Haken, R. K. (2009). Using fluorodeoxyglucose positron emission tomography to assess tumor volume during radiotherapy for nonsmall-cell lung cancer and its potential impact on adaptive dose escalation and normal tissue sparing. Int. J. Radiat. Oncol. Biol. Phys. 73, 1228-1234.

Fournel, P., Robinet, G., Thomas, P., Souquet, P. J., Léna, H., Vergnenégre, A., Delhoume, J. Y., Le Treut, J., Silvani, J. A., Dansin, E., Bozonnat, M. C., Daurés, J. P., Mornex, F., Pérol, M., and Groupe Lyon-Saint-Etienne d'Oncologie Thoracique-Groupe Français de Pneumo-Cancérologie. (2005). Randomized phase III trial of sequential chemoradiotherapy compared with concurrent chemoradiotherapy in locally advanced non-small-cell lung cancer: Groupe Lyon-Saint-Etienne d'Oncologie Thoracique-Groupe Francais de Pneumo-Cancerologie NPC 95-01 Study. J. Clin. Oncol. 23, 5910-5917.

Furuse, K., Fukuoka, M., Kawahara, M., Nishikawa, H., Takada, Y., Kudoh, S., Katagami, N., and Ariyoshi, Y. (1999). Phase III study of concurrent versus sequential thoracic radiotherapy in combination with mitomycin, vindesine, and cisplatin in unresectable stage III non-smallcell lung cancer. J. Clin. Oncol. 17, 2692-2699.

Gandara, D. R., Chanksky, K., Albain, K. S., Leigh, B. R., Gaspar, L. E., Lara, P. N. Jr., Burris, H., Gumerlock, P., Kuebler, J. P., Bearden, J. D. III, Crowley, J., Livingston, R., and Southwest Oncology Group. (2003). Consolidation docetaxel after concurrent chemoradiotherapy in stage IIIB non-small-cell lung cancer: phase II Southwest Oncology Group Study S9504. J. Clin. Oncol. 21, 2004-2010.

Graham, M. V., Purdy, J. A., Emani, B., Harms, W., Bosch, W., Lockett, M. A., and Perez, C. A. (1999). Clinical dose-volume histogram analysis for pneumonitis after 3D treatment for non-small cell lung cancer (NSCLC). Int. J. Radiat. Oncol. Biol. Phys. 45, 323-329.

Hanna, N., Neubauer, M., Yiannoutsos, C., McGarry, R., Arseneau, J., Ansari, R.,Reynolds, C.,
Govindan, R., Melnyk, A., Fisher, W., Richards, D., Bruetman, D., Anderson, T., Chowhan, N., Nattam, S., Mantravadi, P., Johnson, C., Breen, T., White, A., Einhorn, L., Hoosier Oncology Group, and US Oncology. (2008). Phase III study of cisplatin, etoposide, and concurrent chest radiation with or without consolidation docetaxel in patients with inoperable stage III non-small-cell lung cancer: the Hoosier Oncology Group and U.S. Oncology. J. Clin. Oncol. 28, 5755-5760.

Kong, F. M., Ten Haken, R. K., Schipper, M. J., Sullivan, M. A., Chen, M., Lopez, C., Kalemkerian, G. P., and Hayman, J. A. (2005). High-dose radiation improved local tumor control and overall survival in patients with inoperable/unresectable nonsmall-cell lung cancer: long term results of a radiation dose escalation study. Int. J. Radiat. Oncol. Biol. Phys. 63, 324-333.

Le Chevalier, T., Arriagada, R., Quoix, E., Ruffie, P., Martin, M., Tarayre, M., Lacombe-Terrier, M. J., Douillard, J. Y., and Laplanche, A. (1991). Radiotherapy alone versus combined chemotherapy and radiotherapy in nonresectable non-small-cell lung cancer: first analysis of a randomized trial in 353 patients. J. Natl. Cancer Inst. 83, 417-423.

Lee, C. B., Stinchcombe, T. E., Moore, D. T., Hayes, D. N., Halle, J., Rosenman, J. G., Rivera, M. P., and Socinski, M. A. (2009). Late complications of high-dose $(>/=66 \mathrm{~Gy})$ thoracic conformal radiation therapy in combined modality trials in unresectable stage III non-small cell lung cancer. J. Thorac. Oncol. 4, 74-79.

Lievens, Y., Nulens, A., Gaber, M. A., Defraene, G., De Wever, W., Stroobants, S., and Van Den Heuvel, F. (2011). Intensity-modulated radiotherapy for locally advanced non-small-cell lung cancer: a dose-escalation planning study. Int. J. Radiat. Oncol. Biol. Phys. 80, 306-313.

Ling, C. C., Humm, J., Larson, S., Amols, H., Fuks, Z., Leibel, S., and Koutcher, J. A. (2000). Towards multidimensional radiotherapy (MDCRT): biological imaging and biological conformality. Int. J. Radiat. Oncol. Biol. Phys. 47, 551-560.

Machtay, M., Bae, K., Movsas, B., Paulus, R., Gore, E. M., Komaki, R., Albain, K., Sause, W. T., and Curran, W. J. (2010). Higher biologically effective dose of radiotherapy is associated with improved outcomes for locally advanced non-small cell lung carcinoma treated with chemoradiation: an analysis of the radiation therapy oncology group. Int. J. Radiat. Oncol. Biol. Phys. [Epub ahead of print].

MacManus, M. P., Hicks, R. J., Ball, D. L., Kalff, V., Matthews, J. P., Salminen, E., Khaw, P., Wirth, A., Rischin, D., and McKenzie, A. (2001). F-18 fluorodeoxyglucose positron emission tomography staging in radical radiotherapy candidates with non-small-cell lung carcinoma: powerful correlation with survival and high impact on treatment. Cancer 92, 886-895.

Perez, C., Stanley, K., Grundy, G., Hanson, W., Rubin, P., Kramer, S., Brady, L. W., Marks, J. E., Perez-Tamayo, R., Brown, G. S., Concannon, J. P., and Rotman, M. (1982). Impact of irradiation technique and tumor extent in tumor control and survival of patients with unresectable non-oat cell carcinoma of the lung: report by the Radiation Therapy Oncology Group. Cancer 50, 1091-1099.

Pritchard, R. S., and Anthony, S. P. (1996). Chemotherapy plus radiotherapy compared with radiotherapy alone in the treatment of locally advanced, unresectable, non-smallcell lung cancer. Ann. Intern. Med. $125,723-729$.

Rosenman, J. G., Halle, J. S., Socinski, M. A., Deschesne, K., Moore, D. T., Johnson, H., Fraser, R., and Morris, D. E. (2002). High dose conformal radiotherapy for treatment of stage IIIA/IIIB non-small-cell lung cancer: technical issues and results of a phase I/II trial. Int. J. Radiat. Oncol. Biol. Phys. 54, 348-356.

Rosenzweig, K. E., Sim, S. E., Mychalczak, B., Braban, L. E., Schindelheim, R., and Leibel, S. A. (2001). Elective nodal irradiation in the treatment of non-small-cell lung cancer with three-dimensional conformal radiation therapy. Int. J. Radiat. Oncol. Biol. Phys. 50, 681-685.

Salama, J. K., Stinchcombe, T. E., Gu, L., Wang, X., Morano, K., Bogart, J. A., Crawford, J. C., Socinski, M. A., Blackstock, A. W., Vokes, E. E. and Cancer and Leukemia Group B. (2011). Pulmonary toxicity in stage III non-small cell lung cancer patients treated with high dose (74 Gy) 3-dimensional conformal thoracic radiotherapy and concurrent chemotherapy following induction chemotherapy: a secondary analysis of Cancer and Leukemia Group B (CALGB) trial 30105. Int. J. Radiat. Oncol. Biol. Phys. 81, e269-e274.

Sause, W., Kolesar, P., Taylor, S., Johnson, D., Livingston, R., Komaki, R., Emami, B., Curran, W. Jr., Byhardt,
R., Dar, A. R., and Turrisi, A. III. (2000). Final results of phase III trial in regionally advanced unresectable non-small cell lung cancer. Chest 117, 358-364.

Schaake-Koning, C., Van Den Bogaert, W., Dalesio, O., Festen, J., Hoogenhout, J., van Houtte, P., Kirkpatrick, A., Koolen, M., Maat, B., Nijs, A., Renaud, A., Rodrigus, P., SchusterUitterhoeve, L., Sculier, J.-P., van Zandwijk, N., and Bartelink, $\mathrm{H}$. (1992). Effects of concomitant cisplatin and radiotherapy on inoperable non-small-cell lung cancer. $N$. Engl. J. Med. 326, 524-530.

Schild, S. E., McGinnis, W. L., Graham, D., Hillman, S., Fitch, T. R., Northfelt, D., Garces, Y. I., Shahidi, H., Tschetter, L. K., Schaefer, P. L., Adjei, A., and Jett, J. (2006). Results of a phase I trial of concurrent chemotherapy and escalating doses of radiation for unresectable nonsmall-cell lung cancer. Int. J. Radiat. Oncol. Biol. Phys. 65, 1106-1111.

Socinski, M. A., Blackstock, A. W., Bogart, J. A., Wang, X., Munley, M., Rosenman, J., Gu, L., Masters, G. A., Ungaro, P., Sleeper, A., Green, M., Miller, A. A., and Vokes, E. E. (2008). Randomized phase II trial of induction chemotherapy followed by concurrent chemotherapy and dose-escalated thoracic conformal radiotherapy (74 Gy) in stage III non-small-cell lung cancer: CALGB 30105. J. Clin. Oncol. 26, 2457-2463

Socinski, M. A., Morris, D. E., Halle, J. S., Moore, D. T., Hensing, T. A., Limentani, S. A., Fraser, R., Tynan, M., Mears, A., Rivera, M. P., Detterbeck, F. C., and Rosenman, J. G. (2004). Induction and concurrent chemotherapy with high-dose thoracic conformal radiation therapy in unresectable stage IIIA and IIIB nonsmall-cell lung cancer: a dose escalation phase I trial. J. Clin. Oncol. 22, 4341-4350.

Sulman, E. P., Komaki, R., Klopp, A. H., Cox, J. D., and Chang, J. Y. (2009). Exclusion of elective nodal irradiation is associated with minimal elective nodal failure in non-small cell lung cancer. Radiat. Oncol. 4, 5.

Toloza, E. M., Harpole, L., and McCrory, D. C. (2003). Noninvasive staging of non-small cell lung cancer: a review of current evidence. Chest 123, 137S-146S.

Torres-Roca, J. F., Eschrich, S., Zhao, H., Bloom, G., Sung, J., McCarthy, S., Cantor, A. B., Scuto, A., Li, C., Zhang, S., Jove, R., and Yeatman, T. (2005). Prediction of radiation sensitivity using a gene expression classifier. Cancer Res. 65, 7169-7176. 
Vokes, E. E., Herndon, J. E. II, Kelley, M. J., Cicchetti, M. G., Ramnath, N., Neill, H., Atkins, J. N., Watson, D. M., Akerley, W., Green, M. R., and Cancer and Leukemia. (2007). Induction chemotherapy followed by chemoradiotherapy compared with chemoradiotherapy alone for regionally advanced unresectable stage III non-small-cell lung cancer: Cancer and Leukemia Group B. J. Clin. Oncol. 25, 1698-1704.

Wang, L., Correa, C., Zhao, L., Hayman, J., Kalemkerian, G. P., Lyons, S., Cease, K., Brenner, D., and Kong, F. M. (2008). The effect of radiation dose and chemotherapy on overall survival in 237 patients with stage III non-small-cell lung cancer.
Int. J. Radiat. Oncol. Biol. Phys. 73, 1383-1390.

Widesott, L., Amichetti, M., and Schwarz, M. (2008). Proton therapy in lung cancer: clinical outcomes and technical issues. A systematic review. Radiother. Oncol. 86, 154-164.

Yuan, S., Sun, X., Li, M., Yu, J., Ren, R., Yu, Y., Li, J., Liu, X., Wang, R., Li, B., Kong, L., and Yin, Y. (2007). A randomized study of involved-field irradiation versus elective nodal irradiation in combination with concurrent chemotherapy for inoperable stage III non-small-cell lung cancer. Am. J. Clin. Oncol. 30, 239-244.

Zhang, X., Li, U., Pan, X., Xiaoqiang, L., Mohan, R., Komaki, R., Cox,
J. D., and Chang, J. Y. (2010). Intensity-modulated proton therapy reduces the dose to normal tissue compared with intensity-modulated radiation therapy or passive scattering proton therapy and enables individualized radical radiotherapy for extensive stage IIIB non-small-cell lung cancer: a virtual clinical study. Int. J. Radiat. Oncol. Biol. Phys. 77, 357-366.

Conflict of Interest Statement: The authors declare that the research was conducted in the absence of any commercial or financial relationships that could be construed as a potential conflict of interest.
Received: 14 September 2011; accepted: 09 November 2011; published online: 30 November 2011.

Citation: Terakedis $B$ and Sause $W$ (2011) Radiation dose escalation in stage III non-small-cell lung cancer. Front. Oncol. 1:47. doi: 10.3389/fonc.2011.00047

This article was submitted to Frontiers in Thoracic Oncology, a specialty of Frontiers in Oncology.

Copyright (c) 2011 Terakedis and Sause. This is an open-access article distributed under the terms of the Creative Commons Attribution Non Commercial License, which permits use, distribution, and reproduction in other forums, provided the original authors and source are credited. 